\title{
How Good Is Your Time Management?
}

\author{
Kaouther Znaidi ${ }^{1}$, Almas Sabir ${ }^{2}$ \\ ${ }^{1,2}$ Department-Management, University of Hail, Kingdom of Saudi Arabia \\ znkaouther@yahoo.fr
}

\begin{abstract}
Numerous individuals are not generally excellent at the time the board. Subsequently, they are in a steady condition of emergency, and they are not as compelling as they would somehow or another is. When you realize how to deal with your time you oversee what you accomplish. Step through this self-exam test to recognize the parts of time the executives that you need most assistance with. The outcomes will guide towards the particular apparatuses that will assist us with working all the more proficiently. Other individuals are great at time the executives, and therefore, they gain much better ground in less time and exertion. Main focus of the paper is to take the poll and to discover your time the board qualities and shortcomings.
\end{abstract}

Keywords: Time; management; shortcomings; qualities; individuals.

\section{Introduction}

\section{Time Management Test: How Good Are You at Managing Your Time?}

1. Discover how successful your time the executives abilities are-and how they can be improved.

2. Do you think you have great time the board abilities? Or on the other hand do you have this endless inclination that there are never enough hours in the day? (Miller, 2019)

Here are 15 different ways you realize you are great at dealing with your time. (Miller, 2019)

1. You have evaluated every one of your undertakings which you are taking a shot at with a size of high, medium, or low significance.

2. When you get another task you investigate it to begin with to decide the degree of significance and organize it in like manner.

3. You don't end up worrying about due dates and responsibilities you need to finish.

4. You deal with the errands of the most astounding need first.

5. You aren't influenced by diversions that shield you from dealing with basic errands.

6. You have time put aside in your day for timetable arranging.

7. You don't have to take work home with you to complete it or spare it to finish one more day.

8. You set objectives for yourself to enable you to organize the exercises and undertakings you should deal with first.

9. You can put off interferences and manage them after you have finished your errands.

10. Before you start an errand you ensure that the outcomes will merit your time.

11. You have organized your daily agenda or activity plan which encourages you complete your errands in a considerably more opportune way.

12. You go over your needs with your manager or individuals from your family unit to ensure you're on track and everybody is in agreement. (Miller, 2019)

13. You have time put aside in your timetable to manage surprising things that may emerge.

14. You know how much time it takes you to finish different employments that you need to do. (Miller, 2019)

15. You complete errands in an opportune way and needn't bother with any augmentations. 
In the event that you do these things constantly, at that point you are an uncommon gem waiting to be discovered. The vast majority do experience issues accomplishing everything on the above rundown. There's additionally continually something you can improve, so look at certain territories that regardless you may require improvement in. (Miller, 2019)

\section{Zones Where You Can Improve Your Time Management (Miller, 2019)}

1. Objective setting -It is essential to set objectives for yourself and whatever ventures you are dealing with. This will enable you to know the request of significance wherein you have to get things done in and furthermore decide to what extent it will take you to finish them. (Miller, 2019)

2. Organizing -Recognizing what is absolutely critical to finish in some random errand will help hugely in time the board. (Miller, 2019) Plan for the day are an incredible device, however just on the off chance that they are assembled by request of significance. So set aside a few minutes making sense of what you should finish first and after that do it.

3. Oversee intrusions -You can't complete anything in case you're continually getting intruded. That is the reason it's significant that you have devices to oversee interferences. In the event that that implies closing off the telephone for an hour or so multi day, at that point do it, however make sure to utilize that hour shrewdly. (Miller, 2019)

4. Planning -This is the thing that time the board is about. Make your timetable by foreseeing interferences. (Miller, 2019)Along these lines, you ideally won't wind up getting offtimetable ever, consequently keeping away from a ton of stress.

5. Tarrying -Putting off work prompts dreadfully numerous inadequate errands and substantially a lot of pressure. It's significant that in case you're a slowpoke, you deal with improving that.

Chipping away at these territories of time the board will make you significantly more viable at work and home and you'll feel substantially less focused. So now how great is your time the board? (Miller, 2019)

\section{Example to understand time management and self-assessment}

Self-appraisal of your investigation time examples enables you to investigate and assess the scope of choices you make every day concerning the time the board. Overseeing time is an extremely perplexing procedure and self-evaluation gives a few proportions of your qualities and shortcomings.

\begin{tabular}{|c|c|c|c|c|c|}
\hline Do these items reflect you as a student? & No & & & & Yes \\
\hline $\begin{array}{l}\text { 1. I keep a careful record of the dates of upcoming major events } \\
\text { such as tests and assignments. }\end{array}$ & 1 & 2 & 3 & 4 & 5 \\
\hline 2. I often feel really panicky about being behind with my work. & 1 & 2 & 3 & 4 & 5 \\
\hline $\begin{array}{l}\text { 3. During a study sessions, I set small goals and work to achieve } \\
\text { them (e.g., read } 5 \text { pages of text and do three math problems). }\end{array}$ & 1 & 2 & 3 & 4 & 5 \\
\hline 4. I tend to miss classes. & 1 & 2 & 3 & 4 & 5 \\
\hline $\begin{array}{l}\text { 5. If I need to solve a problem quickly, I get help from another } \\
\text { student, the teacher, or other help resources. }\end{array}$ & 1 & 2 & 3 & 4 & 5 \\
\hline $\begin{array}{l}\text { 6. I often miscalculate how much time homework tasks will } \\
\text { take. }\end{array}$ & 1 & 2 & 3 & 4 & 5 \\
\hline 7. I have set up a regular plan for my study activities. & 1 & 2 & 3 & 4 & 5 \\
\hline
\end{tabular}


8. I find my current course load too heavy

9. I begin assignments early so that I will have time to do a good job

10. I have difficulty concentrating while doing homework.

11. I plan ahead so I can be flexible about putting in extra hours if I have a lot of school work to do.

12. I always seem to be behind with my work.

13. I regularly use a day planner to plan my activities.

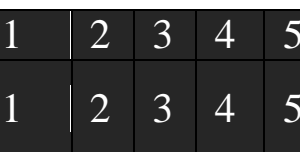

14. My marks tend to suffer because of last minute cramming for tests.

15. Each day I have clear goals what I wish to accomplish.

16. I am easily distracted from school work by my friends, TV, etc.

17. I really enjoy working on the courses I am taking.

18 . I can only work if I feel like working

19. I prioritize tasks effectively.

20. I have a hard time deciding just what school work I should be doing outside of class.

\begin{tabular}{|l|l|l|l|l|}
\hline 1 & 2 & 3 & 4 & 5 \\
\hline 1 & 2 & 3 & 4 & 5 \\
\hline 1 & 2 & 3 & 4 & 5 \\
\hline 1 & 2 & 3 & 4 & 5 \\
\hline 1 & 2 & 3 & 4 & 5 \\
\hline 1 & 2 & 3 & 4 & 5 \\
\hline 1 & 2 & 3 & 4 & 5 \\
\hline 1 & 2 & 3 & 4 & 5 \\
\hline 1 & 2 & 3 & 4 & 5 \\
\hline 1 & 2 & 3 & 4 & 5 \\
\hline 1 & 2 & 3 & 4 & 5 \\
\hline
\end{tabular}

\section{Your scores for each item}

\begin{tabular}{|l|l|l|l|l|l|l|l|l|l|l|}
\hline 1 & 3 & 5 & 7 & 9 & 11 & 13 & 15 & 17 & 19 & Total \\
\hline & & & & & & & & & & \\
\hline 2 & 4 & 6 & 8 & 10 & 12 & 14 & 16 & 18 & 20 & Total \\
\hline & & & & & & & & & & \\
\hline
\end{tabular}

Total for the ODD numbers minus the total for the Even numbers $=$

\section{Understanding your Score}

Odd-numbered things in the stock reflect positive segments of time the board that can add to powerful utilization of time. Indeed numbered things reflect negative parts that can detract from the powerful time the executives. Consequently, on the off chance that you have a positive all out score; this demonstrates a proactive way to deal with overseeing time. On the off chance that your score is negative, your time the board procedures can be improved. Be that as it may, recollect that there is nobody right approach to oversee time. You have to locate the correct methodology for you that will take into account errands to be finished on schedule, without requiring a superhuman exertion. It will likewise guarantee that your feeling of anxiety is sensible.

\section{Introductory Goals}

Think back to your finished self-evaluation. Of the 20 things on the stock, select five things that you feel are significant issues for you. These might be regular practices that are as of now bringing down your fulfillment and potential as an understudy. What might you want to risk improving things?

Utilize the table beneath to contrast your score with a delegate test of different understudies. The table gives percentile rankings. For instance, if your score on the appraisal stock was 7, your percentile positioning is 66 . That implies that your score was higher than 
the scores of $66 \%$ of the delegate test of understudies who finished the poll. Information for the table was gathered from 200 understudies from an assortment of classes and instructive foundations.

Use the table below to compare your score to a representative sample of other students. The table gives percentile rankings. For example, if your score on the assessment inventory was 7 , your percentile ranking is 66 . That means that your score was higher than the scores of $66 \%$ of the representative sample of students who completed the questionnaire.

Data for the table were collected from 200 students from a variety of classes and educational institutions.

\begin{tabular}{||l|l||l|l||l|l||}
\hline Score & Percentile & Score & Percentile & Score & Percentile \\
\hline \hline 31 & 100 & 9 & 73.9 & -7 & 21.3 \\
\hline 26 & 99.5 & 8 & 70.7 & -8 & 20.7 \\
\hline 24 & 98.9 & 7 & 66 & -9 & 19.1 \\
\hline 22 & 98.4 & 6 & 63.3 & -10 & 17 \\
\hline 21 & 96.8 & 5 & 60.1 & -11 & 12.8 \\
\hline 20 & 96.3 & 4 & 55.9 & -12 & 10.1 \\
\hline 19 & 95.7 & 3 & 52.1 & -13 & 8.5 \\
\hline 18 & 93.1 & 2 & 47.3 & -14 & 7.4 \\
\hline 17 & 92 & 1 & 42.6 & -15 & 5.3 \\
\hline 16 & 89.4 & 0 & 38.3 & -16 & 4.3 \\
\hline 15 & 85.6 & -1 & 36.2 & -17 & 3.2 \\
\hline 14 & 85.1 & -2 & 34 & -20 & 2.7 \\
\hline 13 & 83.5 & -3 & 30.9 & -22 & 2.1 \\
\hline 12 & 81.4 & -4 & 28.7 & -23 & 1.6 \\
\hline 11 & 79.3 & -5 & 25 & -25 & 1.1 \\
\hline 10 & 76.6 & -6 & 23.9 & -37 & 0.5 \\
\hline \hline \\
Your Score:
\end{tabular}

Adjusted from: (Fleet and Reaume, 1994).

This report was imitated under the specialist of the Copyright Act, area 29 (Fair Dealing), and is expected to be utilized for instructive purposes as it were. Some other use requires the authorization of the copyright holder (Fleet and Reaume, 1994).

The Top 10 Life Benefits of Time Management (Jarrow, 2013)

"For what reason would it be a good idea for me to deal with my time?"

The basic answer is that time the executives cause you to remain over your undertakings and accomplish more.

However, there is considerably more.

Time the executives benefit you in all aspects of your life.

1. Why Time Management?

2. Why care about time the board?

The fundamental reason is that time the executives benefit you.

You may state, "I would prefer not to invest the additional exertion... to deal with my time... to remain sorted out."

Apologies, however, those are pardons.

"Time the board shouldn't take as much time as necessary, yet rather make additional time for you." (Tweet this Quote) 
It's additionally about guaranteeing you invest your energy where it is important most to you.

\section{Life Benefits of Time Management}

1. Time the board means remaining over your time, life, and exercises.

2. It shouldn't require extraordinary exertion, however, it requires discipline.

3. Be that as it may, the advantages of time the executives far exceed the work required (Jarrow, 2013).

Here are 10 Life Benefits of Time Management: (Jarrow, 2013).

1. Less Stress - Managing your time can straightforwardly lessen your anxiety. Less amazement. Less tight due dates. Less surging from assignment to-errand and here and there.

2. Accomplish More - obviously, being profitable is one of the principal objectives of time the executives. When you know about what you have to do, you can all the more likely deal with your remaining task at hand. You will most likely get more (of the correct errands) done in less time.

3. Less Rework - Being composed outcomes in less modify and slip-ups. Overlooked things, subtleties, and guidelines lead to additional work. How regularly do you need to do an undertaking more than once? Or on the other hand make an additional excursion since you overlook something? (Jarrow, 2013).

4. Less Life Friction and Problems - How frequently do you make your very own issues? Regardless of whether it is an overlooked arrangement or missed a due date, not dealing with your time brings about expanded life grating. Abstain from making your own issues by arranging and getting ready for your day.

5. All the more Free Time - We can't make additional time, yet you can utilize it by dealing with your time. Jarrow, (2013) indeed, even straightforward activities like moving your drive or completing your work early can deliver more relaxation time in your life.

6. Less Wasted Time - When you realize what you have to do, you squander less time out of gear exercises. Rather than pondering what you ought to do straight away, you would already be able to be a stage in front of your work.

7. More Opportunities - Being over your time and work creates more chances. The brisk riser consistently has more choices. Also, karma supports readied.

8. Improves Your Reputation - Your time the board notoriety will continue you. At work and in life you will be known as dependable. Nobody is going to address whether you are going to appear, do what you state you will do or comply with that time constraint (Jarrow, 2013).

9. Less Effort - A typical misinterpretation is that time the board requires additional exertion. In actuality, legitimate time the board makes your life simpler. Things require less exertion, regardless of whether it is pressing for that outing or wrapping up that venture.

10. Additional Time Where it Matters - Managing your time is allocating your time where it has the most effect. Time the executives enable you to invest your energy in the things that issue most to you (Jarrow, 2013). 


\section{Deal with Your Time, Improve Your Life}

1. Time the executives is tied in with investing your energy in the correct spots, and on the correct things (Jarrow, 2013).

2. It's tied in with knowing your needs, commitments, and calendar (Jarrow, 2013).

3. When you deal with your time, you advantage in all everyday issues (Jarrow, 2013).

\section{Review of Literature}

\subsection{Previous Researches and outcomes}

A recent research on managing time named, 'How to Motivate Yourself When You Don't Have a Deadline by Saunders, September 04, 2019, explained time management in a very nice way. Elizabeth is a time management coach and the founder of Real Life E Time Coaching \& Speaking. She is author of How to Invest Your Time like Money and Divine Time Management. According to her, due dates are incredible powers in our work, flagging what's most significant, constraining center, and driving errands to culmination. That is the reason extends that don't have a due date can mull on your undertaking list for a considerable length of time, months, or even years (Elizabeth, 2019).

In some cases, this happens because an undertaking is vague, exhausting, or muddled. You normally deprioritize it at whatever point conceivable, because chipping away at it feels awkward. Yet, on different occasions, you don't intend to stay away from the venture. Elizabeth, (2019) you just never get to it, since things with clear due dates feel all the more squeezing.

You likely don't get a ton of outer fire for postponements on non-due date undertakings; however, inside it can feel disappointing when tasks sit immaculately. Also, with significant yet not-critical things, there's the uneasiness that at any minute somebody may get some information about their status, and you will have nothing to appear (Elizabeth, 2019).

At last, she focused on how you can have a go at making a remunerating some portion of the way toward completing works. For example, you could release yourself to a café or a recreation center on the off chance that you complete an errand while you're there. Elizabeth, (2019) When you do this, you're consolidating a pleasurable involvement with the need to concentrate on an undertaking that you probably won't chip away at something else.

Propelling yourself to do non-due date errands is a test, yet it's not difficult. Elizabeth, (2019) in another research, 'Time Spent in Face-to-Face Patient Care and Work outside the Examination Room 'by Andrew Gottschalk, and Susan A. Flocked, November 1, 2005 vol. 3 no. 6488-493, highlights the importance of time for patients. In their exploration, nearly one portion of an essential consideration doctor's workday is spent on exercises outside the diagnostic room, predominately centered on development and documentation of consideration for patients not physically present (Andrew and Susan, 2005). National appraisals of visit term overestimate the mix of up close and personal time and time spent on visit-explicit work outside the diagnostic room by $41 \%$ (Andrew and Susan, 2005).

In a book'15 Secrets Successful People Know About Time Management: The Productivity Habits of 7 Billionaires, 13 Olympic Athletes, 29 Straight-A Students, and 239 Entrepreneurs 'By (writer) Kevin Kruse, raises certain questions like; Is it true that you are exhausted and overpowered? Imagine a scenario in which a couple of new propensities could expand your efficiency by $5 x$ or even 10x. Suppose you had an additional hour every day to peruse, exercise, rest, or to go through with your family (Kruse). 
New York Times smash hit creator, Kevin Kruse, presents the exceptional discoveries of his investigation regarding time management of ultra-beneficial individuals. Kruse, In light of overview research and meetings with tycoons, Olympic competitors, straight-An understudies, and more than 200 business visionaries - including Mark Cuban, Kevin Harrington, James Altucher, John Lee Dumas, Grant Cardone, and Lewis Howes- - Kruse responds to the inquiry: what are the key to outrageous profitability? You will learn:

- How to fix tarrying with "Time Travel"

- How to spare 8 hours every week with "3 Questions"

- How to recognize your genuine top needs

- How to get the opportunity to zero messages in your inbox consistently (Kruse).

First Things First (1994) is a self-improvement guide composed by Stephen Covey, A. Roger Merrill, and Rebecca R. Merrill. It offers a period the board approach that, whenever set up as a propensity, is expected to enable an individual to accomplish "viability" by adjusting oneself to "First Things". The methodology is a further improvement of the methodology advanced in Covey's The Seven Habits of Highly Effective People and different titles (Covey, Merrill, and Merrill, 1996).

The book declares that there are three ages of time the board: original undertaking records, second-age individual coordinators with due dates and third-age esteems explanation as joined in the Franklin Planner (Covey, Merrill, and Merrill, 1996).Utilizing the similarity of "the clock and the compass," the creators state that recognizing essential jobs and standards gives a "genuine north" and reference when choosing what exercises are most significant, with the goal that choices are guided not simply by the "clock" of planning however by the "compass" of direction and qualities. Declaring that individuals have a need "to live, to cherish, to learn, and to leave an inheritance" they propose moving past "direness" (not equivalent to the quadrant II in a Cartesian arrange framework) (Covey, Merrill, and Merrill, 1996).

In the book, Covey depicts a system for organizing work that is gone for long haul objectives, to the detriment of undertakings that give off an impression of being critical; however, they are in certainty less significant. He utilizes a period the board definition credited to Eisenhower, ordering errands into whether they are pressing and whether they are significant, perceiving that significant undertakings may not be earnest, and dire assignments are not really important. This is his $2 \times 2$ framework: grouping errands as dire and non-critical on one hub, and significant or non-significant on the different pivot. His quadrant 2 has the things that are non-dire yet significant. These are the ones he accepts we are probably going to disregard; at the same time, we should concentrate on accomplishing adequacy (Covey, Merrill, and Merrill, 1996).

Significant things he distinguished by concentrating on a couple of key needs and jobs which will fluctuate from individual to individual, at that point recognizing little objectives for every job every week, so as to keep up a comprehensive life balance. One instrument for this is a worksheet that rundowns up to seven key jobs, with three weeks after week objectives per job, to be assessed and booked into every prior week different arrangements involve all accessible time with things that appear to be earnest, however, are not significant. This idea is shown with a story that urges individuals to "place the enormous shakes first." (Covey, Merrill, and Merrill, 1996).

The assignment is displayed by him as a significant piece of time for the executives. Fruitful assignment, as indicated by Covey, centers on results and benchmarks that are to be 
concurred ahead of time, instead of on recommending definite work plans. (Covey, Merrill, and Merrill, 1996).

\section{Research Methodology}

A random sample of 230 participants belonging to different professional groupings, friends and relatives was obtained from online surveys, mails and manually distributed questionnaires that includes all types of participants. Static content questions and dichotomous Survey Question types are used.

With compelling time the board, we can assume responsibility for our time and jump over our plan for the day. Begin by examining how great your time the executive's abilities are at this moment, with our test.

At that point make a plunge directly into the center abilities of time the board: prioritization, planning and core interest. Investigate the verifiable speculations and ways to deal with time the executives to comprehend what's appropriate for you. Also, we'll help you to manage some basic time the executive's difficulties, for example, delay, dead time and interferences. At long last, rouse yourself by figuring out how to set objectives, and find what it is that spurs you.

\section{Discussion}

\subsection{Research Analysis}

a. Is your work station a mess, or is it tidy?

\begin{tabular}{|c|c|}
\hline OPTION & RESPONSE \\
\hline It is tidy & 112 \\
\hline It is a mess & 118 \\
\hline
\end{tabular}

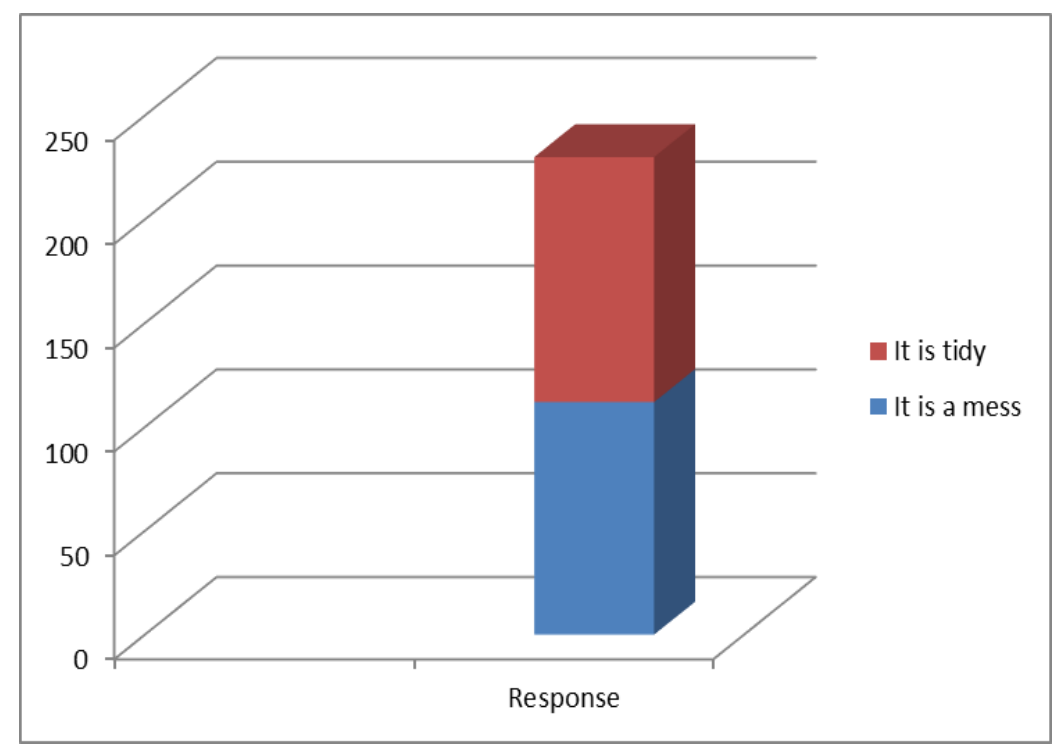


Do you feel focused or diverted when you get the opportunity to work? Here's one reason you might not have considered: not having a perfect work area at work

Without a doubt, you've presumably heard things like "definitely, my work area is muddled, yet so was Einstein's". This thought having a jumbled work area is something worth being thankful for has turned out to be considerably more typical over the most recent couple of years. However, oh dear, that doesn't make it right and we will complete a touch of exposing. Out of 230 respondents, 118 respondents considered it was a mess. It shows a wreck can stop your stream. On the off chance that you discover your eyes floating to the miscellaneous items strewn around your work area, those minutes are lost time. All the more critically, it's interference. This can be especially counterproductive when you're "in-thezone" and wrenching out quick, quality work.

Indeed, even 15 minutes/week has an immense effect. I like to do this on Friday evenings. It gives me a feeling of goals and makes ready for a positive begin on Monday morning. In the event that you need to go greater, cleaning up toward the finish of every workday can be an incredible rhythm.

\section{b. Do you spend at least an hour a week planning for the next three weeks?}

\begin{tabular}{|c|c|}
\hline OPTION & RESPONSE \\
\hline Yes & 211 \\
\hline No & 19 \\
\hline
\end{tabular}

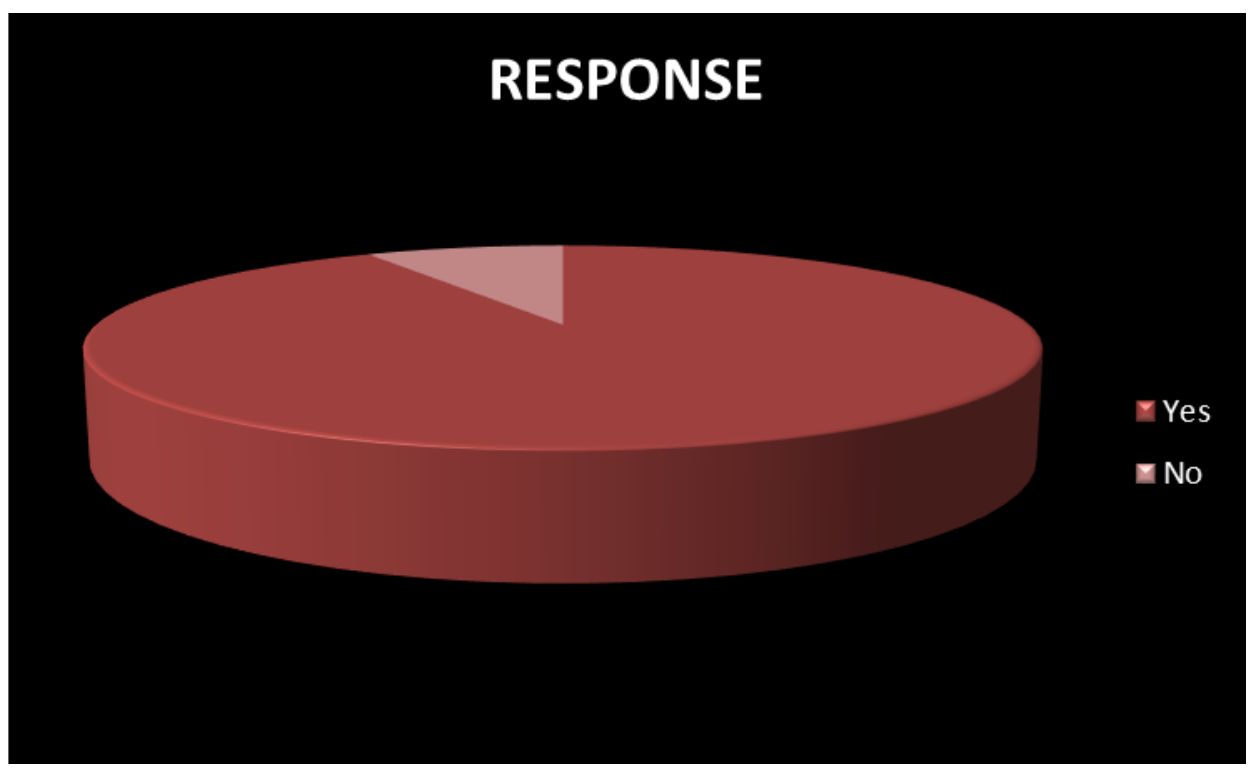

Specialist's state the 40-hour working week did not depend on the perfect complete hour's people can work gainfully. In spite of the fact that the eight hours out of each day is sensible when contrasted with work hours in the late eighteenth century. Laborers were relied upon to $\log$ as long as 16 hours. This was gone for supporting the nonstop working 
necessities of generally manufacturing plants. In any case, it later turned out to be certain that such long working hours were unsustainable. It was somewhat harsh and counter-beneficial.

Most of the respondents (211 out of 230) spend at least an hour a week planning for the next three weeks. Work-life parity has consistently been a battle. In any case, an expanded worry for laborers' rights combined with the intensity of computerization has made a move. Certain enterprises don't require the same number of working hours any longer, and the worldwide pattern - particularly in Europe - inclines toward a four-day weeks' worth of work.

Does it work? Could individuals achieve a similar sum in four days as they can in five? Also, assuming this is the case, for what reason isn't everybody doing it?

The four-day weeks' worth of work has turned into an interesting issue as of late, as innovation has acquainted new ways with increment efficiency. Be that as it may, in all actuality, the thought has been on individuals' psyches for some time now.

In March and April of 2018, the firm ran a trial that diminished their weeks' worth of work from 40 hours to 32 hours, for the majority of its 240 representatives, while as yet paying similar pay rates. They procured a couple of scientists to record the outcomes quantitatively, and what they discovered shows positive help for the four-day work week:

1. $24 \%$ more representatives felt they could effectively adjust their work and individual lives.

2. Stress diminished by $7 \%$ among everybody included.

3. By and large work fulfillment expanded by $5 \%$.

\section{c. Do you operate according to a plan or are you mostly reactive?}

\begin{tabular}{|c|c|}
\hline OPTION & RESPONSE \\
\hline According to plan & 195 \\
\hline Mostly reactive & 35 \\
\hline
\end{tabular}

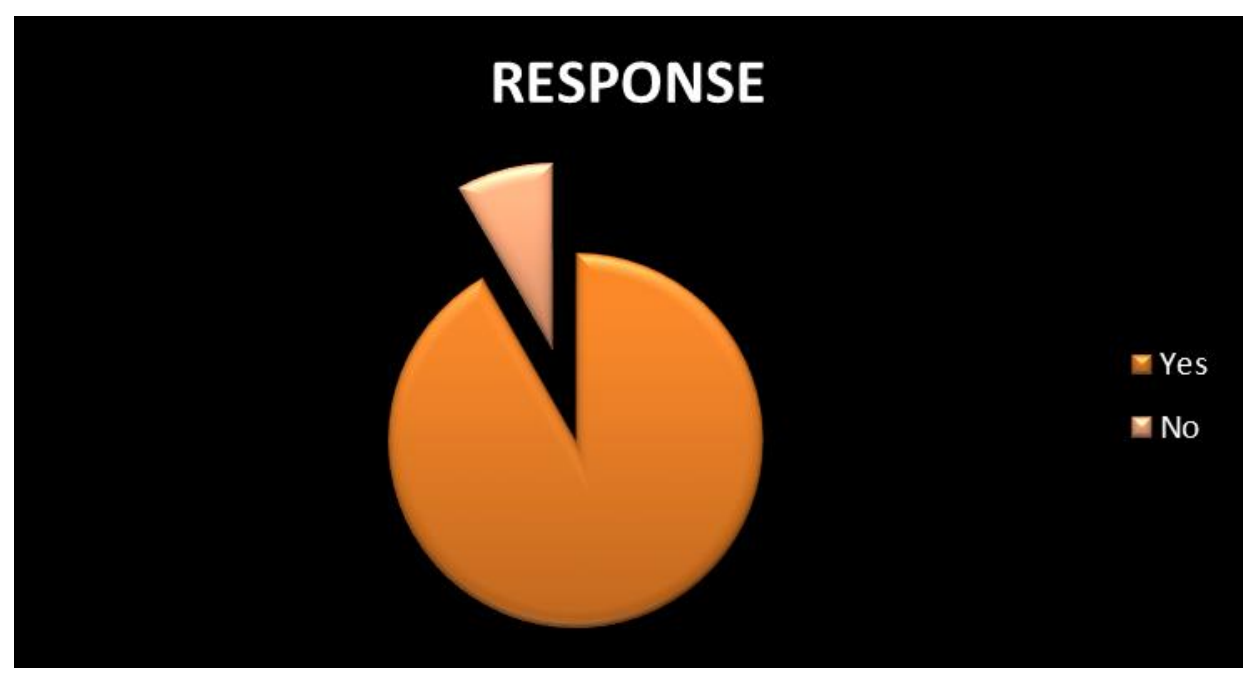


Be Proactive is tied in with assuming liability for your life. You can't continue accusing everything on your folks or grandparents. Proactive individuals perceive that they are "reaction capable." They don't accuse hereditary qualities, conditions, conditions, or molding for their conduct. They realize they pick their conduct. Receptive individuals, then again, are regularly influenced by their physical condition. They discover outside sources to fault for their conduct. On the off chance that the climate is great, they feel better. On the off chance that it isn't, it influences their frame of mind and execution, and they accuse the climate. Most of the respondents go to plan.

These outer powers go about as upgrades that we react to. Between the boost and the reaction is your most noteworthy power- - you have the opportunity to pick your reaction. One of the most significant things you pick is the thing that you state. Your language is a decent marker of how you see yourself. A proactive individual uses proactive language- - I can, I will, I like, and so on. A receptive individual uses responsive language- - I can't, I need to, assuming as it were. Receptive individuals accept they are not in charge of what they state and do- - they must choose between limited options.

\section{d. Do you use prioritization decision matrix or do you just go by gut feel?}

\begin{tabular}{|l|c|}
\hline \multicolumn{1}{|c|}{ OPTION } & RESPONSE \\
\hline $\begin{array}{l}\text { Prioritization } \\
\text { decision matrix }\end{array}$ & 43 \\
\hline Gut Feel & 187 \\
\hline
\end{tabular}

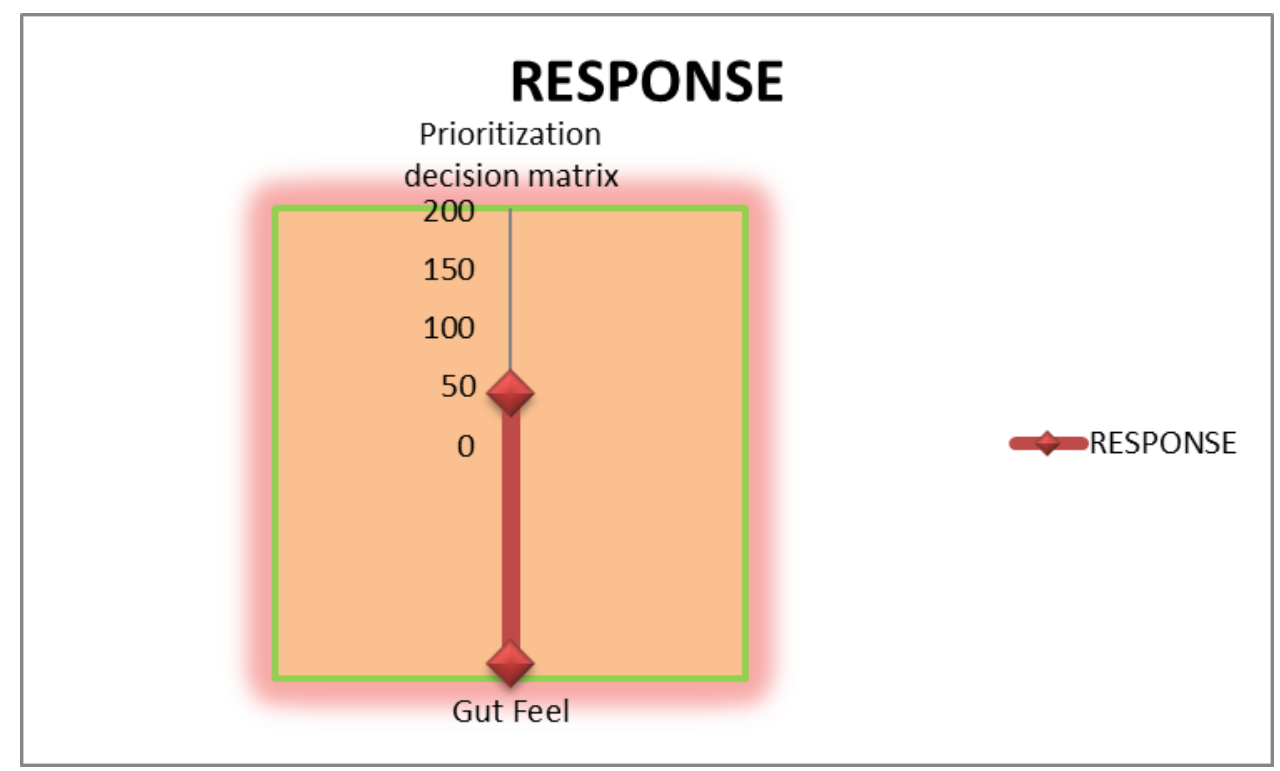

A lot of thought goes into deciding what features to prioritize. These decisions are influenced by customer feedback, market research, or innovating technology. But the real struggle is how to prioritize your list. As a help worker when item impediments begin making clients insane, you will drop those issues on item engineers. 
Be that as it may, this represents a colossal issue for engineers particularly if item input continues getting dropped on them while they're amidst a cycle.

The cerebrum utilizes a blend of rationale and feeling when settling on choices of any sort. That particular feeling, intrinsic to us as people, is instinct. We have the ability to feel and in this way the capacity to know things without intentionally thinking. The "premonition" is genuine, and we use it constantly.

Here is no such thing as a simply intelligent choice. The cerebrum utilizes a blend of rationale and feeling when settling on choices of any sort. That particular feeling, natural to us as people, is instinct. We have the ability to feel and along these line the capacity to know things without intentionally thinking. The "premonition" is genuine, and we use it constantly. In our survey also, almost all respondents goes for GUT feelings (187 respondents)

"Going with our gut," be that as it may, suggests vulnerability and does not ensure a decent result. In some cases, all the hard data we need is directly there for us, and we can depend on rationale without inclining a lot on our gut impulses. Yet, when it's not, wouldn't it be pleasant to realize that our gut gives superior to a 50/50 possibility of achievement?

Every one of us can, in any case, sharpen our instinct regardless of whether we don't have a solid reasoning inclination somehow. For example, somebody without a predominant Social inclination still has some degree of Social instinct that will be improved by each communication with individuals. As a rule, any encounter is a decent encounter, and the more we have of them, the more precise our guts become.

\section{Recommendations and suggestions}

Time management: 6 recommendations for in field workers

1. Plan your day in advance. It is advisable to plan your day in advance.

2. Prioritize tasks. Prioritize your tasks for the day.

3 . Focus on your goals and priorities. You must focus on your target for the day.

4. Take breaks. Working non-stop may result in burnout. .

5. Track your time.

6. Assess where your time is wasted.

\section{Delight ought to consistently be the objective. Work can be play.}

We get so made up for a lost time in hastiness that we neglect to appreciate what we're doing. Notwithstanding when we center on working more brilliant, we're still frequently excessively centered on completing things. This ought to never be the point. Continuously ask yourself: What would I be able to do to invest more energy getting a charge out of what I'm doing?

The objective ought to be to mastermind your responsibilities such that you're glad experienced the subtleties of your day by day life, even while you're working. This may sound like a pipe dream, yet it's more conceivable than any time in recent memory in this day and age. Be interested. Be available to circumstance. Know yourself. Grasp your interests.

\section{Conclusion}

One of the best aptitudes you can have in life is a ground-breaking and powerful time the board. In case you're not dealing with your time well, it is extremely unlikely you're going to achieve your objectives at work and the life outside of it. Of course, you may gain some 
ground. In any case, your time the board will be a daunting task in the event that you don't take as much time as necessary truly. For individuals who waste and waste the valuable brief period they do have, they know very well how troublesome accomplishing even somewhat troublesome objectives can be.

In all actuality, time is the best equalizer throughout everyday life. Regardless of your identity, your age, pay, sexual orientation, race or religion, you have a similar measure of time as anyone else. Regardless of whether you're ridiculously wealthy or down and out, your time is the equivalent. It's not about how much time you have. It's about how viably you deal with your time.

In conclusion, time management is a very important skill to be learned and to be mastered in order to have a better lifestyle. By managing well-timed, you will no longer suffer from stress and your works/tasks will be done on time and with great quality.

Time the executives are a significant ability to be educated and to be aced so as to have a superior way of life. By overseeing admirably time, you will never again experience the ill effects of pressure and your works/undertakings will be done on schedule and with extraordinary quality. Keep in mind that it is essential to have the frame of mind to change your timetables and to change stalling. Likewise, consider the majority of the clarified techniques that are extremely useful to accomplish a superior time the board. It is essential to include, that sports likewise give a supportive hand to time the board, and furthermore grant your body to be solid and to have a superior group of friends.

Regardless of whether we dole out a dollar incentive to it or not, time is important to us. Consider it: How a lot of your run of the mill work week do you spend worried about not having sufficient opportunity to finish an assignment or achieve an objective?

There are heaps of various approaches to handle the issue of time the executives - you can download applications, modify your rest time, make records, and so on. However, in the event that you don't completely comprehend why it's significant for you to all the more likely deal with your time, those applications and records aren't going to support you. On the off chance that you don't have the inspiration to utilize them, you won't.

You need to initially take a gander at the 10,000 foot view. Understand why dealing with your time adequately is significant, and what you remain to pick up from it. You can begin by looking into these 8 reasons time the board is significant:

1. Time is limited- No matter how you cut it, there are just 24 hours in multi day. That concerns you, and to your collaborator who just appears to be ready to do a large portion of the measure of work you do. However, it likewise applies to the previous colleague who reliably achieves more than you, and was advanced therefore. In the event that you need to ascend through the positions, you need to recognize the significance of figuring out how to deal with this constrained asset.

2. You can achieve more with less effort- When you figure out how to assume responsibility for your time; you improve your capacity to center. What's more, with expanded center comes upgraded effectiveness, since you don't lose energy. You'll begin to easily get through errands all the more rapidly (the workday will likewise appear to fly by).

3. Improved basic leadership ability- Whether you depend on a period lumping strategy or find the intensity of rundown making, you'll before long find that a pleasant side advantage of good time the board aptitudes is the capacity to settle on better choices. When you feel in a rush and need to settle on a choice, you're bound to make a hasty judgment without completely thinking about each choice. That prompts poor choice 
making. Through viable time the board, you can dispose of the weight that originates from feeling like you need more time. You'll begin to feel increasingly quiet and in charge. At the point when the opportunity arrives to inspect choices and settle on a choice, rather than racing through the procedure, you can set aside some effort to painstakingly think about every alternative. What's more, when you're ready to do that, you lessen your odds of settling on an awful choice.

4. Become increasingly fruitful in your career- Time the board is the way to progress. It enables you to assume responsibility for your life as opposed to following the progression of others. As you achieve all the more every day, settle on increasingly cool headed choices, and feel more in charge, individuals take note. Pioneers in your business will come to you when they have to complete things. What's more, that expanded presentation helps place you in line for headway openings.

5. Learning openings are everywhere- Obviously, the more you learn, the more important you are to your manager. Also, extraordinary learning openings are around you, on the off chance that you have time to stop and exploit them. When you work all the more productively, you have that time. You can assist with that new item dispatch your advancement group's been taking a shot at. Volunteer to help have your organization's open house. Indeed, even simply getting a charge out of a decent lunch with colleagues in different offices can demonstrate educational. The more you find out about your organization and your industry, the better your odds of establishing a positive connection on the C-suite.

6. Lessen stress- When you don't have control of your time, it's anything but difficult to wind up inclination hurried and overpowered. What's more, when that occurs, it very well may be difficult to make sense of to what extent it will take to finish an errand. (Think about when you were going to miss a due date and were quickly attempting to complete the undertaking. On the off chance that somebody dumped a shock around your work area right then and there and asked you to what extent it would take to complete the unexpected errand, how might you even start to answer their question?)Once you figure out how to deal with your time, you never again subject yourself to that degree of stress. Other than it being better for your wellbeing, you have a clearer image of the requests on your time. You're better ready to appraise to what extent a given assignment will take you to finish, and you realize you can comply with the time constraint.

7. Available time is necessary- Everyone needs time to unwind and loosen up. Tragically, however, a considerable lot of us don't get enough of it. Between employments, family duties, errands, and upkeep on the house and the yard, the vast majority of us are unable to discover even 10 minutes to sit and do nothing. Having great time the board abilities causes you find that time. When you're occupied, you're accomplishing more. You aggregate additional time during your time that you can utilize later to unwind, loosen up, and plan for a decent night's rest.

8. Self-control is valuable- When you practice great time the board, you rule out delaying. The better you get at it, the more self-control you learn. This is a profitable ability that will start to affect different parts of your life where an absence of control has shielded you from accomplishing an objective. 


\section{The positive cycle of good time management}

Glancing through the rundown over, it's anything but difficult to see the multiplicative impact of time the executives. Great time the executives enables you to achieve more in a shorter timeframe, which prompts all the more extra time, which gives you a chance to exploit learning openings, brings down your pressure, and causes you center, which prompts more vocation achievement. Each advantage of time the executives improves another part of your life. You should simply kick the cycle off.

\section{References}

Andrew G., and Susan A. F. (2005). 'Time Spent in Face-to-Face Patient Care and Work outside the Examination Room. vol. 3 no. 6 488-493.

Covey, S., R., Merrill A., R., and Merrill, R., R. (1996). First Things First. Free Press.

Elizabeth, G., S. (2019). 'How to Motivate Yourself When You Don't Have a Deadline by Saunders [3],

Fleet, J., and Reaume, D. (1994). Power Over Time: Student Success with Time Management. Canada: Harcourt Brace.

Jarrow, C. (2013). Time Management Ninja. https://timemanagementninja.com/2013/10/thetop-10-life-benefits-of-time-management/

Kruse, K. '15 Secrets Successful People Know About Time Management: The Productivity Habits of 7 Billionaires, 13 Olympic Athletes, 29 Straight-A Students, and 239 Entrepreneurs https://www.bookdepository.com/15-Secrets-Successful-People-KnowAbout-Time-Management-Kevin

Kruse/9780985056438? redirected=true\&utm_medium=Google\&utm_campaign=Base 1 \&utm_source=SA\&utm_content=15-Secrets-Successful-People-Know-About-TimeManagement

Miller, I. (2019). Time Management Test: How Good Are You at Managing Your Time? https://www.customerservicemanager.com/time-management-test/

\section{Appendix}

\section{Questionnaires Used In Survey}

Q1 - Generally, are you a good time manager? Yes $\mathrm{No} O$

Q2 - Do you have clear and distinct goals?

Yes $\mathrm{O}$

No O

Q3 - Do you operate according to a plan or are you mostly reactive? According to a plan $\bigcirc \quad$ mostly reactive $O$

Q4 - Do you know about the time management grid?
Yes $\mathrm{O}$
No O

Q5 - Do you often have days that can be described as busy but not very productive? Yes $\mathrm{No} O$

Q6 - Do you work with people who tend to waste your time?

Yes

No O 
Q7 - Is your work station a mess, or is it tidy?
It is a mess $\mathrm{O}$
It is tidy $O$

Q8 - Do you keep going strong, all day long? Or as the day progresses, do you tend to run out of energy?

I keep going all day long! $\bigcirc \quad$ I run out of energy in the afternoon. $\bigcirc$

Q9 - Could you be more efficient?

Yes $\mathrm{O}$

No O

Q10 - Do you spend at least an hour a week planning for the next three weeks?

Yes $\mathrm{No} O$

Q11 - Do you take good notes or do you rely too much on your unaided memory?

I take good notes $\bigcirc \quad$ I rely on my unaided memory $\bigcirc$

Q12 - If you have a plan, do you have sufficient will power to stick to it?
Mostly yes $\bigcirc$
often no $\mathrm{O}$

Q13 - Have you ever considered that your whole life depends upon your ability to make good decisions?

It has not occurred to me $\bigcirc \quad$ It has often occurred to me $\bigcirc$

Q14 - Do you realize that there are five fundamental types of decision matrix?

Yes $\mathrm{O}$

No - what are they?

Q15 - Do you tend to alternate endlessly between two options? Should I or shouldn't I?

Yes I do $\mathrm{No}$ I don't $\mathrm{O}$

Q16 - Do you know the difference between prioritization by value, and prioritization by logical sequence?
Yes $\mathrm{O}$
No O

Q17 - Do you seek to always do the most valuable thing, or not?

Yes I do $\bigcirc \quad$ No. I don't always do the most valuable thing $\bigcirc$

Q18 - Do you use prioritization decision matrix or do you just go by gut feel?

Prioritization decision matrix $\bigcirc$ Gut Feel $\bigcirc$

Q19 - Do you delegate sufficient work?

Yes $\mathrm{O}$

No O

Q20 - If you do delegate sufficient work do you use SMART goals to help you to describe the task?

Yes $\mathrm{N}$ No

Q21 - If you don't delegate tasks is it because you think it is quicker to do it yourself?

Yes $\mathrm{No} O$

Q22 - If you don't delegate tasks is it because you think the other person may do it wrong?

Yes $\mathrm{O}$ No O

Q23 - If you don't delegate is it because you feel guilty for delegating work onto others?

Yes $\mathrm{O}$

No O 